\title{
PENJAMIN MUTU PROGRAM STUDI
}

\author{
Umasih
}

Email : umasih_sejarah@yahoo.co.id

Universitas Negeri Jakarta

\section{PENJAMINAN MUTU PROGRAM STUDI}

Disampaikan dalam Seminar dan Rapat Kerja

Tahunan P3SI

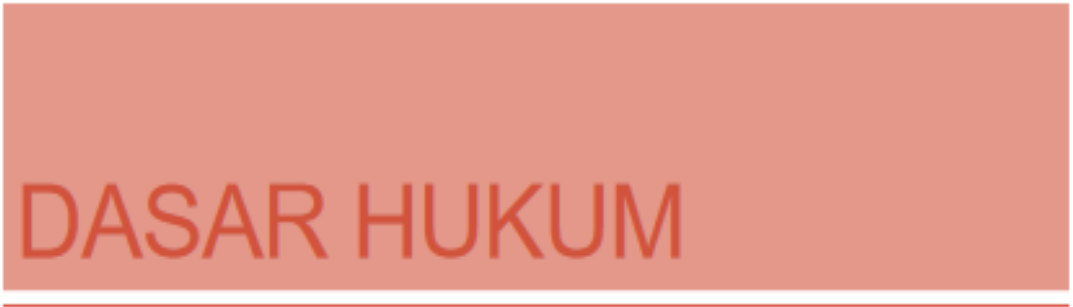

UU NO. 12 TAHUN 2012 TENTANG PENDIIKAN TINGGI (UU DIKTI)

Pasal 7 ayat 1 : Menteri bertanggung jawab atas penyelenggaraan

Pendidikan Tinggi.

-Ayat 3 huruf c: Peningkatan penjaminan mutu, relevansi, keterjangkauan,

pemerataan yang berkeadilan, dan akses Pendidikan Tinggi secara

berkelanjutan; 


\section{BAB III}

\section{PENJAMINAN MUTU}

Sistem Penjaminan Mutu

Standar Pendidikan Tinggi

Akreditasi

Pangkalan Data Pendidikan Tinggi

Lembaga Layana Pendidikan Tinggi

\section{INTI SPMI}

\section{Pasal 52 (ayat 1); Penjaminan mutu Pendidikan Tinggi merupakan kegiatan sistemik untuk meningkatkan mutu Pendidikan Tinggi secara berencana dan berkelanjutan. - (ayat 2); Penjaminan mutu sebagaimana dimaksud pada ayat (1) dilakukan melalui penetapan, pelaksanaan, evaluasi, pengendalian, dan peningkatan standar Pendidikan Tinggi}




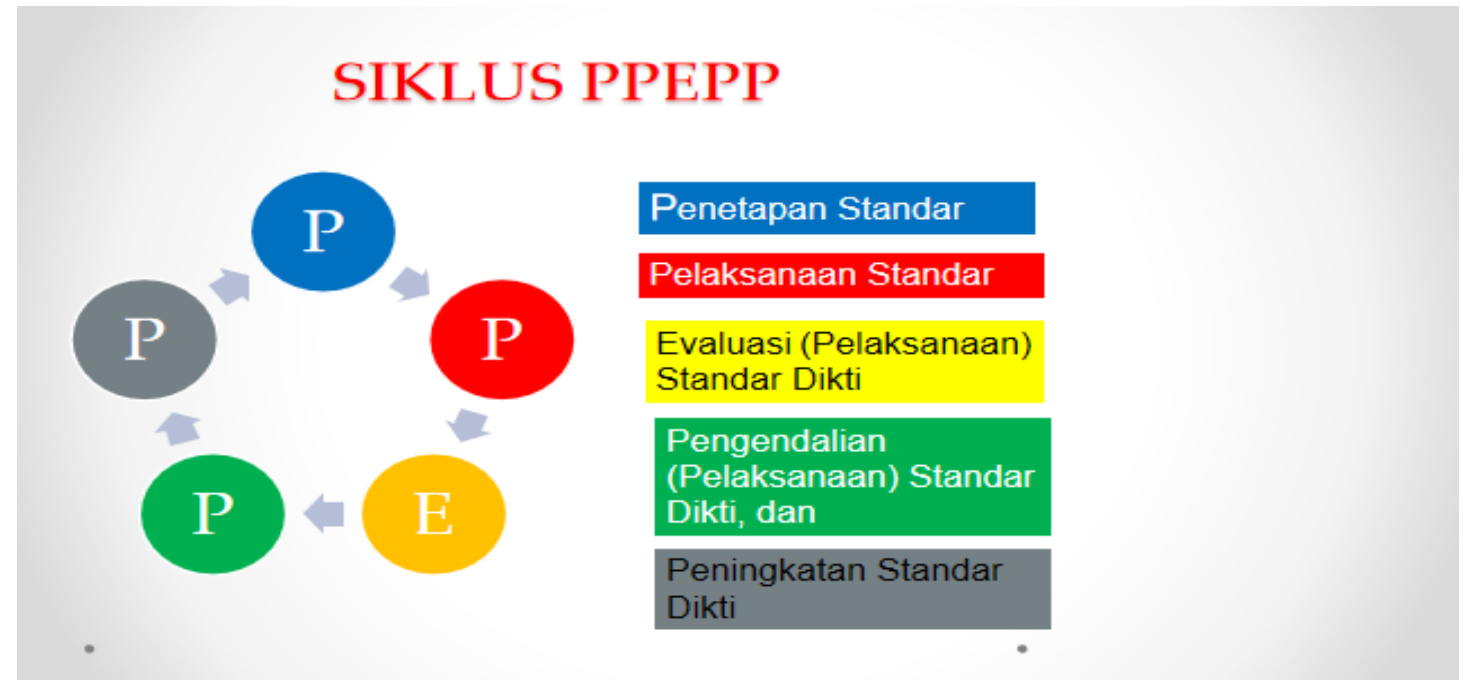

ACCREDITATION IS NOT A GOAL

(AKREDITASI BUKAN TUJUAN)

Akreditasi Program Studi adalah kegiatan penilaian untuk menentukan kelayakan Program Studi.

Akreditasi merupakan Sistem Penjaminan Mutu Eksternal sebagai bagian dari Sistem Penjaminan Mutu Pendidikan Tinggi. 


\section{BAGAIMANA MENCAPAI TUJUAN}

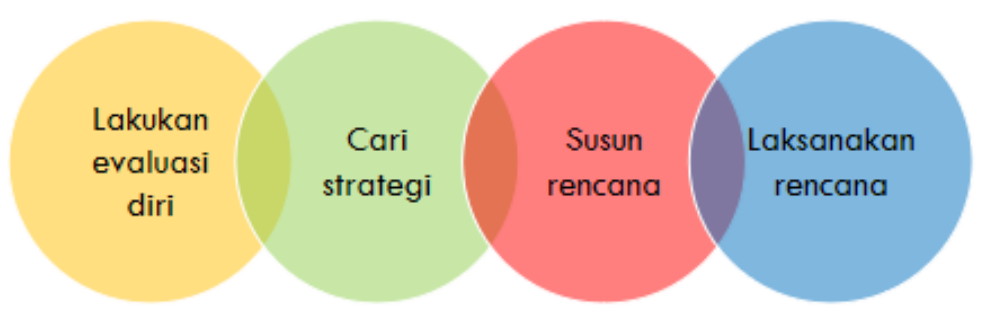

\section{BAGAIMANA MENCAPAI TUJUAN}

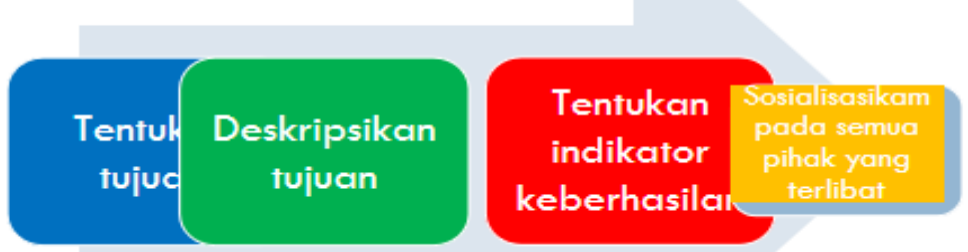




\section{INTI SPME (AKREDITASI)}

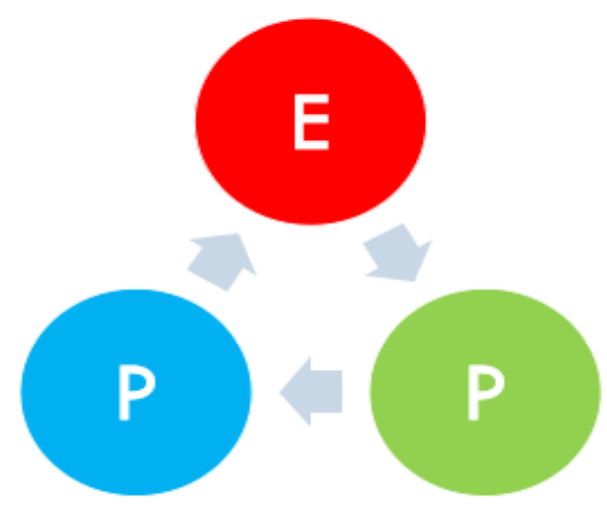

\section{Permenristekdikti No. 32 Tahun 2016}

Pasal 45 (ayat 2): Tahapan Akreditasi

Evaluasi data dan informasi;

Penetapan status akreditasi dan peringkat terakreditasi;

Pemantauan dan evaluasi status akreditasi dan peringkat terakreditasi. 


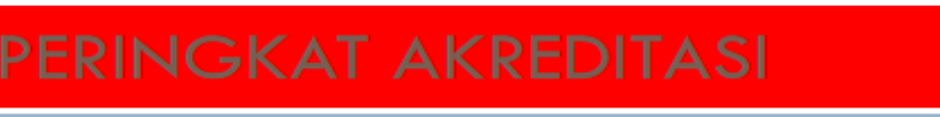

TERAKREDITASI BAIK

TERAKREDITASI BAIK SEKALI

TERAKREDITASI UNGGUL

\begin{tabular}{|c|c|c|}
\hline No & CURRENT STANDARS & NEW CRITERIA \\
\hline 1 & Visi, Misi, Yujuan dan Strategi & Visi, Misi, Yujuan dan Strategi \\
\hline 2 & $\begin{array}{l}\text { Tata Pamong, Tata Kelola, } \\
\text { kepemimpinan, dan Penjaminan Mutu }\end{array}$ & $\begin{array}{l}\text { Tata Pamong, Tata Kelola, dan } \\
\text { Kerjasama }\end{array}$ \\
\hline 3 & Mahasiswa dan Alumni & Mahasiswa \\
\hline 4 & Sumber daya manusia & Sumber Daya Manusia \\
\hline 5 & $\begin{array}{l}\text { Kurikulum, Pembelajaran dan Akademik } \\
\text { Atmosfir }\end{array}$ & Keuangan, Sarana Prasarana \\
\hline 6 & $\begin{array}{l}\text { Keuangan, Sarana Prasarana dan } \\
\text { Sistem Informasi }\end{array}$ & Pendidikan ) \\
\hline 7 & $\begin{array}{l}\text { Penelitian, Pengabdian pada } \\
\text { Masyarakat dan Kerjasama }\end{array}$ & Penelitian \\
\hline 8 & & Pengabdian pada Masyarakat \\
\hline 9 & & Luaran dan Capaian Tridarma PT \\
\hline
\end{tabular}

99 | Seminar Nasional Sejarah ke 4 Jurusan Pendidikan Sejarah Universitas Negeri Padang 


\section{APORAN KINERJA PT/PS}

BERISI 5 KELOMPOK BESAR DATA :

1. Tata pamong, tata kelola dan kerjasama

2. Mahasiswa

3. Sumber daya manusia

4. Keuangan, sarana dan prasarana

5. Luaran dan capaian

\section{A. CAKUPAN EVALUASI DIRI}

\section{PENGANTAR}

RINGKASAN EKSEKUTIF

PENDAHULUAN

a. Latar Belakang

1) Dasar Penyusunan

2) Tim Penyusun dan Tanggung jawabnya

3) Mekanisme Kerija Penyusunan LED

b. Kondisi Eksternal 


\section{LAPORAN EVALUASI DIRI}

BERISI 4 BAGIAN :

CAKUPAN EVALUASI DIRI

KRITERIA

ANALISIS DAN PENETAPAN PROGRAM

PENGEMBANGAN INSTITUSI

PENUTUP

Lanjutan

c. Profil Institusi/UPPS

1) Sejarah Institusi/ UP \& PS

2) Visi, Misi, Tujuan, Strategi dan Tata Nilai

3) Organisasi dan Tata Kerja

4) Mahasiswa dan Lulusan

5) Dosen dan Tenaga Kependidikan

6) Keuangan, Sarana dan Prasarana

7) Sistem Penjaminan Mutu

8) Kinerja Institusi 
1. Visi, Misi, Tujuan, dan Strategi

2. Tata Pamong, Tata Kelola, dan Keriasama

3. Mahasiswa

4. Sumber Daya Manusia

5. Keuangan, Sarana, dan Prasarana

6. Pendidikan

7. Penelitian

8. Pengabdian kepada Masyarakat

9. Luaran dan Capaian Tridharma

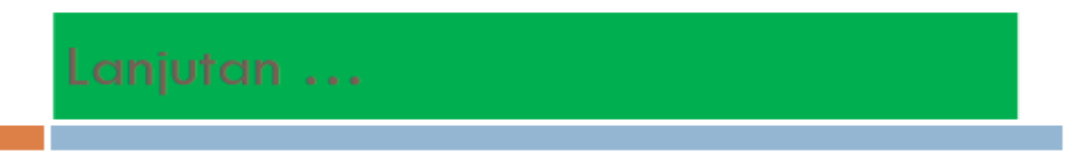

C. ANALISIS DAN PENETAPAN PROGRAM PENGEMBANGAN INSTITUSI

1. Analisis capaian kinerja

2. Analisis SWOT atau analisis lain yang relevan

3. Strategi pengembangan

4. Program Keberlanjutan

D. PENUTUP 


\section{DESKRIPSI SETIAP KRITERIA}
a) Latar Belakang
b) Kebijakan
c) Mekanisme Penetapan dan Strategi Pencapaian Standar
d) Indikator Kinerja Utama
e) Indikator Kinerja Tambahan
f) Evaluasi Capaían Kinerja
g) Penjaminan Mutu
h) Kepuasan Pengguna
i) Kesimpulan hasil evaluasi ketercapaian standar dan tindak lanju

\section{TERIMA KASIH}




\section{ILMU SEJARAH DALAM PEMBELAJARAN SEJARAH DI PT

\author{
WASINO \\ JURUSAN SEJARAH, FAKULTAS ILMU SOSIAL, UNNES \\ wasino@mail.unnes.ac.id \\ Hp.081325750881
}

\section{Sejarah adalah Pembelajaran}

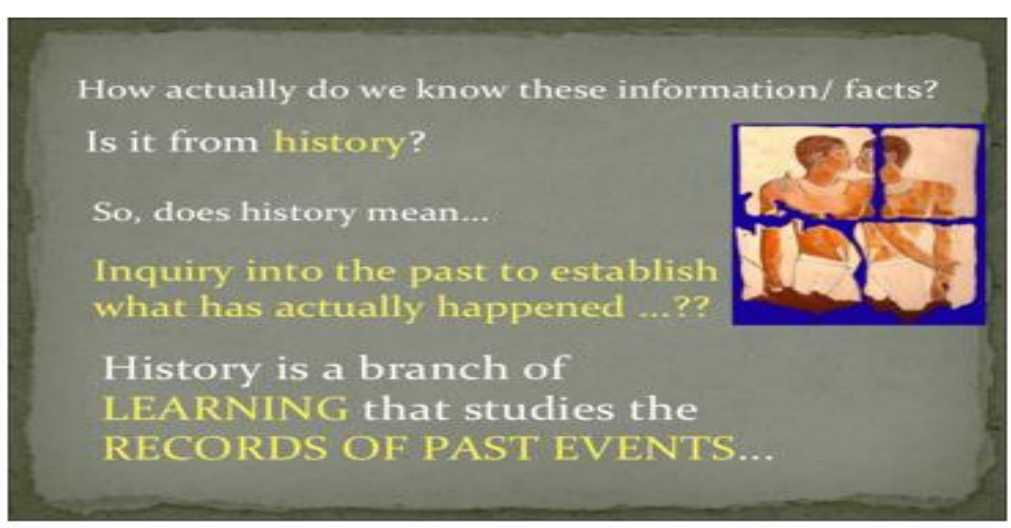

ILMU SEJARAH

1. Metode

2. Teori-metodologi

3. Sumber sejarah

4. Fakta Sejarah

5. Narasi Sejarah 
Dari kejadian menjadi sejarah

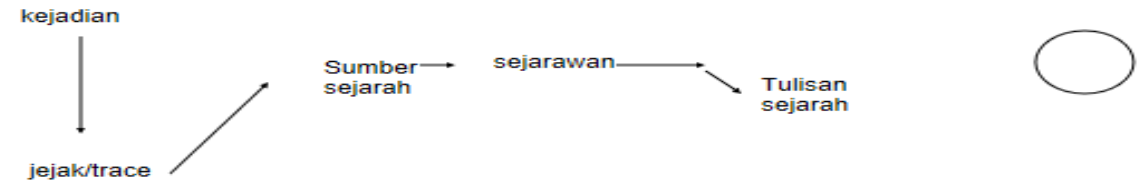

\section{SEJARAH DI PT}

- Diajarkan dalam:

1. Prodi Ilmu Sejarah

2. Prodi Pendidikan Sejarah

3. Prodi Lain

\section{Kajian Sejarah}

- Konseptual

- Teoretis

- Berbasis Riset sejarah

- Sumber sejarah (tertulis, lisan, artefak, media digital).

\section{Isu-isu dalam kelas sejarah}

- Isu-isu kekinian

- Isu-isu kontekstual

- Isu-isu nasional, internasional

- Isu-isu dalam media sosial

Dicari justifikaasinya di masa lampau 


\section{Konteks Kekinian}

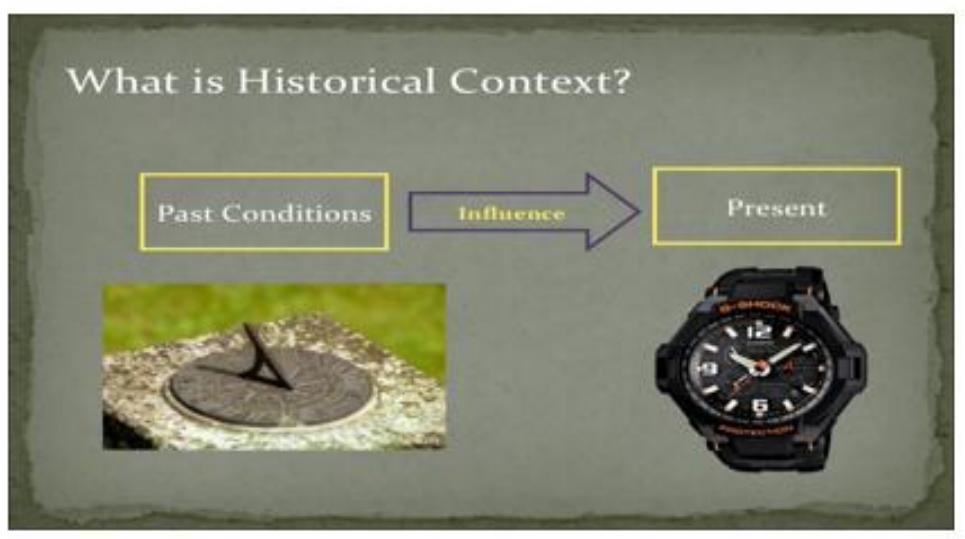

\section{Komunikasi akademik}

- Perlu komunikasi akademik antara ilmuwan sejarah dengan ilmuwan pendidikan sejarah.

- Temuan dalam penelitian sejarah bisa digunakan sebagai bahan pembelajaran sejarah.

- Mengkomunikasikan dengan ahli-ahli pendidikan.

- Mengkomunikasikan dengan ahli Ilmu Sosial dan Studi Sosial.

- Menemukan "model" pendidikan sejarah yang merupakan hasil dialog antara Imu Sejarah dan Ilmu Pendidikan.

\section{Isu-isu}

Historiografi (tradisional, kolonial, Indonesiacentris, postcolonial, public history, digital history)

- Orang-orang tertindas

- Kapitalsme

- Kekuasaan dan Pemerintahan

- Perubahan Sistem hukum

- Perubahan sistem ekonomi

- Agama dan hubungan antar etnik

- Nasionalisme (politik, ekonomi, budaya)

- Revolusi-revolusi besar dunia (politik, ekonomi, teknologi dan informasi) dan pengaruhnya terhadap Indonesia-lokal. 


\section{PEMBELAJARAN SEJARAH DI PT}

- materi sejarah

Pengolahan: Geneaologi, kronologi, tematik.

- model pembelajaran

$-\mathrm{PBL}$

-Research base Learning-Inquiry

-Field Study

-Archief based

-Role playing

-Critical thinking

-debat

\section{Dalam praktik}

- Dalam setiap universitas guru memiliki cara sendiri dalam mengajar.

- Diskusi menjadi metode umum dalam setiap universitas dan tidak bagus bagi individual

- Pendekatan induksi. Bisa bekerjasama dengan asosiasi sejarawan, interview dengan topok-topik sudah dibuat oleh dosen

- Menulis dan diskusi

- National bibliorgaphy dimiliki jurusan sejarah

- Seminar. Misalnya untuk pengajaran sejarah ekonomi, termasuk mahasiswa jadi panitia seminar

- Presentasi

- Membaca essai, mendiskusikannya dg grup kecil

- Membaca ulang dan menilai karya sendiri

\section{Penutup}

- Pembelajaran Sejarah Berbasis pada Isu-isu masa kini.

- Cari Justifikasi Fakta Sejarah

- Gunakan bukti-bukti sejarah (arsip, sumber lisan, sumber kebendaan, sumber ausdio visual dan digital)

- Ciptakan suasan pembelajaran yang melahran Kajian kritis.

- Dialogkan dengan model-model pembelajaran yang dikembangkan ahli pendidikan yang relevan

- Temukan model pembelajaran sejarah yang tepat. 